\title{
Erratum
}

Due to an unfortunate error, the date of reception and the Communicating Editor for the article "Isolation and culture of protoplasts of pigeonpea (Cajanus cajan L.)" by B. Ketan Sarangi, N. Kuchuk and Y. Yu. Gleba in Volume 11, issue 9, 1992 pp. 462-465 were published incorrectly. The correct information is given below:

Plant Cell Reports (1992) 11:462-465

\section{Isolation and culture of protoplasts of pigeonpea (Cajanus cajan L.)}

\section{Bijaya Ketan Sarangi, Nickolay Kuchuk, and Yuri Yu. Gleba}

Institute of Cell Biology and Genetic Engineering, Ukrainian Academy of Sciences, Acad. Lebedev Street 1, Kiev 252143, Ukraine

Received January 9, 1992/Revised version received May 8, 1992 - Communicated by I. K. Vasil 